University of Nebraska - Lincoln

DigitalCommons@University of Nebraska - Lincoln

2004

\title{
How Predation Risk Affects the Temporal Dynamics of Avian Leks: Greater Sage Grouse versus Golden Eagles
}

Adam R. Boyko

Purdue University, boyko@purdue.edu

Robert M. Gibson

University of Nebraska-Lincoln, rgibson@unl.edu

Jeffrey R. Lucas

Purdue University, jlucas@bilbo.bio.purdue.edu

Follow this and additional works at: https://digitalcommons.unl.edu/bioscifacpub

Part of the Life Sciences Commons

Boyko, Adam R.; Gibson, Robert M.; and Lucas, Jeffrey R., "How Predation Risk Affects the Temporal Dynamics of Avian Leks: Greater Sage Grouse versus Golden Eagles" (2004). Faculty Publications in the Biological Sciences. 174.

https://digitalcommons.unl.edu/bioscifacpub/174

This Article is brought to you for free and open access by the Papers in the Biological Sciences at DigitalCommons@University of Nebraska - Lincoln. It has been accepted for inclusion in Faculty Publications in the Biological Sciences by an authorized administrator of DigitalCommons@University of Nebraska - Lincoln. 


\title{
How Predation Risk Affects the Temporal Dynamics of Avian Leks: Greater Sage Grouse versus Golden Eagles
}

\author{
Adam R. Boyko, ${ }^{1, \star}$ Robert M. Gibson, ${ }^{2, \dagger}$ and Jeffrey R. Lucas ${ }^{1, \ddagger}$
}

1. Department of Biological Sciences, Purdue University, West Lafayette, Indiana 47907-2054;

2. School of Biological Sciences, University of Nebraska, Lincoln, Nebraska 68588-0118

Submitted September 30, 2002; Accepted July 2, 2003;

Electronically published January 28, 2004

Online enhancements: appendix, table.

AвSTRACT: Leks often attract predators as well as mates, yet most evolutionary models have assumed that sexual selection, not predation, drives lekking behavior. We explored the influence of predation on lek dynamics using a stochastic dynamic game model based on the lek-breeding greater sage grouse (Centrocercus urophasianus) and its principal avian predator, the golden eagle (Aquila chrysaetos). The model predicts time-dependent male lek attendance as a function of factors affecting both mating success (female arrival rate, male numbers, and social status) and predation risk (eagle arrival rate and group size). Dominant males are predicted to arrive sooner and leave later than subordinates, especially if mating skew is high, predation risk is low, or the relationship between lek size and female arrival rate is weak. Both high mean levels of predation risk and small lek size should reduce lek attendance, but the relative tendency of predators to attack large versus small leks has little influence on predicted lekking behavior. Field observations confirmed the predicted effects of female arrival rate, lek size, male dominance, and weatherdependent predator arrival rates on lek departure times. Predicted effects of female arrival rates and male dominance on seasonal lek attendance were also supported. Our model provides an empirically supported adaptive explanation for short-term lek dynamics. It also suggests alternative interpretations for phenomena previously invoked to support the hotshot and skew models of lek formation.

Keywords: lek mating system, dynamic game theory, greater sage grouse, mating skew, density dependence, predation.

\footnotetext{
* E-mail: boyko@purdue.edu.

† E-mail: rgibson2@unl.edu.

₹ E-mail: jlucas@bilbo.bio.purdue.edu.
}

Am. Nat. 2004. Vol. 163, pp. 154-165. (c) 2004 by The University of Chicago. 0003-0147/2004/16301-20362\$15.00. All rights reserved.
Predation is both a major cost of courtship behavior (Andersson 1994) and an important determinant of sociality (Pulliam and Caraco 1984). It is therefore not surprising that predation has been repeatedly invoked to explain the spectacular social courtship displays of lek-breeding animals (Lack 1968; Wiley 1974; Oring 1982; Trail 1987). Predators have been observed in field studies of many lekking species (Höglund and Alatalo 1995), but we lack compelling empirical evidence that males join leks to reduce predation. One reason is that, with the exception of some swarming insects and chorusing anurans (Ryan et al. 1981; Neems et al. 1992), most lekking animals are long lived and experience correspondingly low mortality rates. As a result, even long-term field studies usually do not provide enough observations of predation to reveal whether predation risk declines with increasing group size (Höglund and Alatalo 1995). We can avoid this difficulty by investigating whether individuals respond adaptively to factors, including group size, that change the trade-off between mate acquisition and predation risk. This approach has been widely used in studies of animal courtship (Candolin and Voight 1998 and references therein; Warner and Dill 2000) but has rarely been applied to leks (Kalas et al. 1995). Instead, most evolutionary models have assumed leks to be the product of sexual selection (Bradbury 1981; Bradbury et al. 1986; Beehler and Foster 1988; Gibson 1992; Widemo and Owens 1995; Kokko 1997).

In this article we develop and test a stochastic dynamic game model that analyzes how the risk of predation by golden eagles, Aquila chrysaetos, affects the temporal dynamics of greater sage grouse, Centrocercus urophasianus, leks. The golden eagle is the principal diurnal predator of adult sage grouse and, although observations of successful predation are scarce, numerous field studies have documented attacks by eagles on lekking males (Wiley 1973; Hartzler 1974; Bradbury et al. 1989a; Gibson and Bachman 1992). Data from our long-term field studies in eastern California have allowed us to identify factors that affect the exposure of lekking grouse to eagle attack. Our studies also indicate that males face a trade-off between remaining on the lek to court females and exposing themselves to 
infrequent but potentially lethal attacks by this major predator (R. M. Gibson, unpublished data). Our goal in this article is to investigate how factors modulating this tradeoff influence male time allocation to lek display versus alternative off-lek activities. Because of the problem's complexity, we begin by developing a model and then test its predictions using data from a long-term field study.

\section{The Model}

We model male sage grouse lekking decisions as a stochastic dynamic game in which each male from a population has the option of attending or avoiding a single lek (see appendix in the online edition of the American Naturalist for a detailed description of the model and justification of parameter values). At the beginning of the lekking season, we assume the population contains $N_{\max }$ males. During the season (March 30-May 20), males can attend the lek from 90 min before sunrise until $210 \mathrm{~min}$ after or until an eagle is sighted. Off-lek mortality during the day, overnight mortality, and mortality between breeding seasons (henceforth "winter mortality") are considered constant and always lower than on-lek mortality, which depends on weather conditions (windy days are more dangerous than calm days because of higher eagle activity) and the number of other males on the lek (dilution effect; Hamilton 1971; Dehn 1990). We assume that males belong to one of five dominance levels and that dominant males achieve proportionately more matings than subordinates according to the mating skew parameter, $\alpha$. Male dominance is fixed during a season but changes probabilistically between seasons, although the behavior of the model is largely insensitive to the exact dominance transition probabilities (details in online appendix). We assume that male age and dominance are uncorrelated. Male mating success in this species is affected by multiple factors, including lek attendance, territorial status, and female choice; female choice, in turn, involves multiple cues provided by males, their territories, and the behavior of other females (Gibson and Bradbury 1985; Gibson et al. 1991). We therefore use "dominance" as a shorthand for the suite of phenotypic characteristics affecting expected mating success.

Each morning of the lekking season is split into $t$ intervals, and for each interval, males must choose between two alternatives: being on or off the lek. There are no constraints on movement to or from the lek, except that an eagle arrival causes the lek to disband for the rest of the day. We assume that all matings occur on the lek and that on-lek mating success is a function of male dominance, the dominance levels of the other males on the lek, and the expected rate of female arrival onto the lek (itself a function of time, date, and weather). Thus, males must decide when the survival cost (in terms of reduced future reproductive success) outweighs the reproductive benefit (in terms of increased current reproductive success) of attending the lek. We assume males behave probabilistically such that when there is a large fitness difference between being on or off the lek, they almost always make the optimal decision, but when little or no difference exists, they are ambivalent (see McNamara et al. 1997).

Initially, we assume that female and predator arrival rates are independent of lek size and that there is a linear relationship between mating skew and dominance status. Later, we relax these assumptions.

\section{Model Predictions}

Despite the fact that individuals are not constrained by how many times per day they can enter or leave the lek, for all simulated conditions no male should visit the lek more than once per morning in the evolutionarily stable strategy (ESS). To illustrate simulation outcomes, we plot the data in two complementary ways. First, for males of a given dominance level, we plot decisions to enter or leave the lek as a function of time of day and stage of the season (e.g., fig. 1). For brevity we present data for the lowest-status ("subordinate") and highest-status ("dominant") birds only. Under all simulated conditions, the decisions of males of intermediate dominance were bounded by these extremes. Second, we plot numbers of birds on the lek as a function of time of day for different stages of the season, weather conditions, and population sizes (e.g., fig. 2).

\section{Baseline Conditions}

We start by assuming a linear relationship between mating skew and dominance status and that lek size does not affect the arrival rates of either predators or females. For these conditions, the model predicts that dominant birds should arrive at the lek earlier in the day and leave later than subordinates (fig. 1). In addition, all males should attend the lek for shorter periods of time (both with respect to time of year and time of day) on windy days compared with calm days. Thus, when eagle predation is more likely (i.e., on windy days), males should attend the lek only when female arrival rates are high. The result is that total lek size should peak in the middle of the breeding season and just after dawn when female arrival rates are at their peak (fig. 2). Finally, leks in smaller populations $\left(N_{\max }=12\right)$ should form for shorter periods than leks in larger populations $\left(N_{\max }=50\right.$; fig. 1$)$. This is particularly noticeable on windy days when, for example, no lek should form in small populations at days 6 and 36, but leks should form on these days in larger populations (fig. 2). Males in larger populations, and therefore males on larger leks, 
(A) $N_{\max }=12$, subordinate, calm

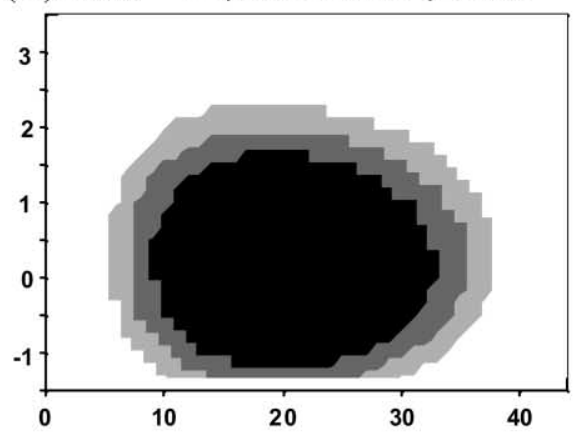

(C) $N_{\max }=12$, dominant, calm

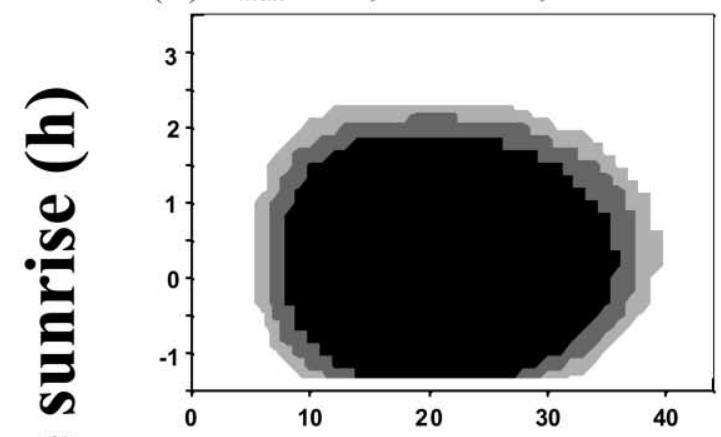

(E) $N_{\max }=50$, subordinate, calm

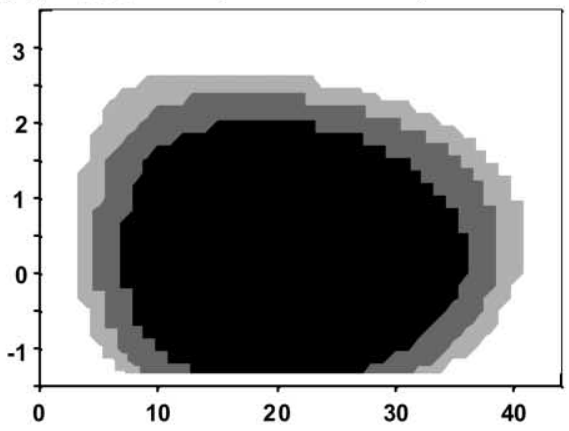

(G) $N_{\max }=50$, dominant, calm

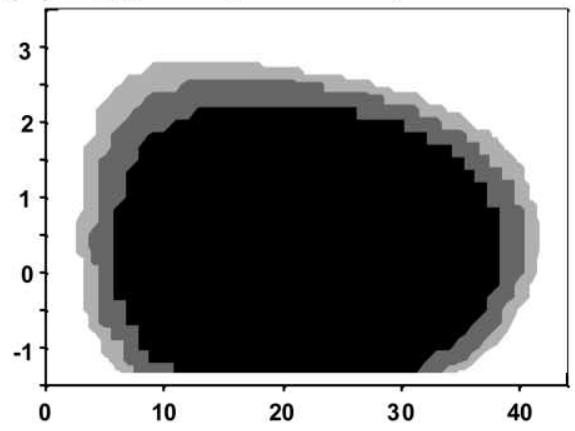

(B) $N_{\max }=12$, subordinate, windy

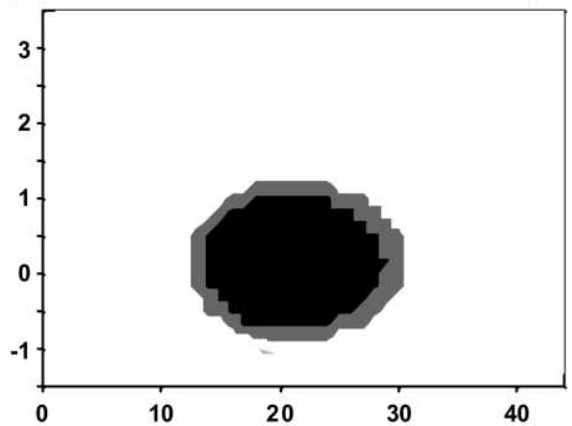

(D) $N_{\max }=12$, dominant, windy

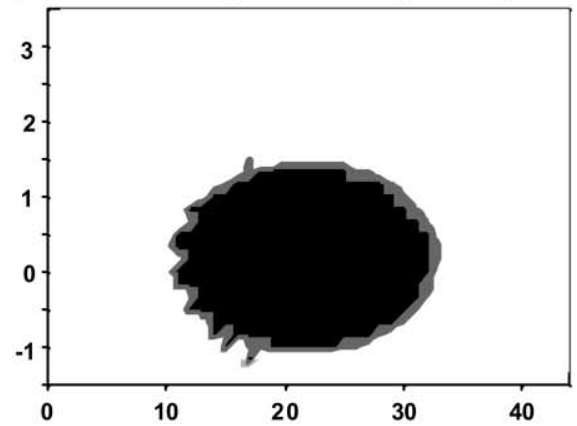

(F) $N_{\max }=50$, subordinate, windy

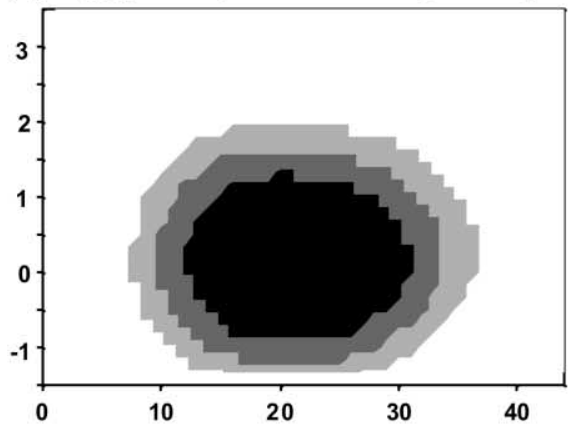

(H) $N_{\max }=50$, dominant, windy

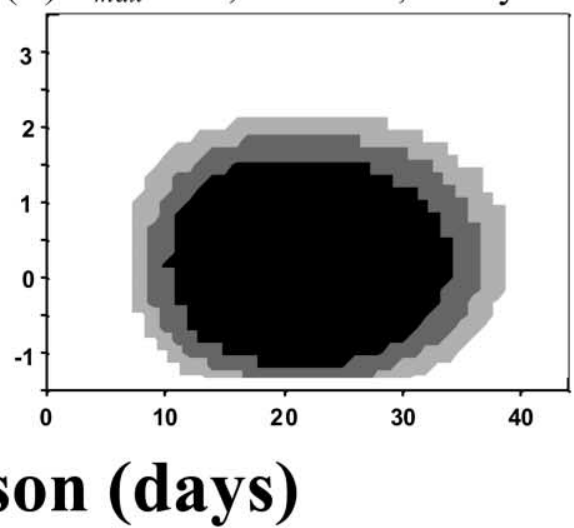

Figure 1: Population size effects: predicted lek attendance decisions for populations starting with 12 or 50 males. Lek attendance is plotted as a function of time of year and time of day for birds of either high- or low-dominance status and for calm and windy days. The decision to enter the lek is probabilistic (with $0 \leq P_{\text {onlek }} \leq 1$ ). There are four probability ranges symbolized by increased levels of shading, with the black representing $P_{\text {onlek }}>0.75$ and white representing $P_{\text {onlek }} \leq 0.25$. This simulation is the result of baseline conditions. 
can "afford" to attend the lek at marginally lower female arrival rates because predators attack a single bird at random from the lek; thus, individual risk diminishes with increasing lek size.

\section{Mating Skew}

We simulated three relationships between female access and male dominance status: linear (baseline, medium skew), square root (low skew), and squared (high skew). For these functions the effects of skew on lek dynamics were sufficiently weak that they are most easily seen with population profiles (fig. 3; the decision matrix is not shown for any of these results). We found that an increased mating skew reduces the size of the lek and its duration (fig. 3 ). Regardless of mating skew intensity, subordinates always arrive at the lek after dominants and leave before them, but as mating skew increases, subordinates should arrive even later and leave even earlier than they would with a low mating skew (data not shown). Presumably, high mating skew reduces the chances that subordinates mate, thereby reducing the period of time that lek attendance is profitable for these males. High mating skew also slightly reduces the period of lek attendance for dominant males because the loss of subordinates during marginal lekking times reduces the dilution effect and increases predation risk on the lek.

\section{Predator Arrival Rates}

Although our field data are consistent with the baseline assumption that predator arrival rates are independent of lek size, larger leks might be attacked more often because they are more conspicuous. We therefore considered three possible relationships between lek size and predator arrival rate: no effect (baseline), square root (weak effect), and squared (strong effect). Furthermore, we calibrated these new functions such that the average male mortality rate was identical for each (see online appendix). Thus, these predator-arrival functions differed in their lek-size dependence but not in their overall predation intensity. Our results (not shown) indicate that male lekking behavior does not change across these three conditions. Thus, the relative shape of the relationship between predation risk and lek size has almost no effect on lekking behavior.

In contrast, the mean level of predation risk has a marked effect on lekking behavior. We tested this by comparing the model results under baseline conditions with results from a model where predator arrival rates were twice the baseline rates, thereby altering the predation intensity but not its lek-size dependence. Under these con-

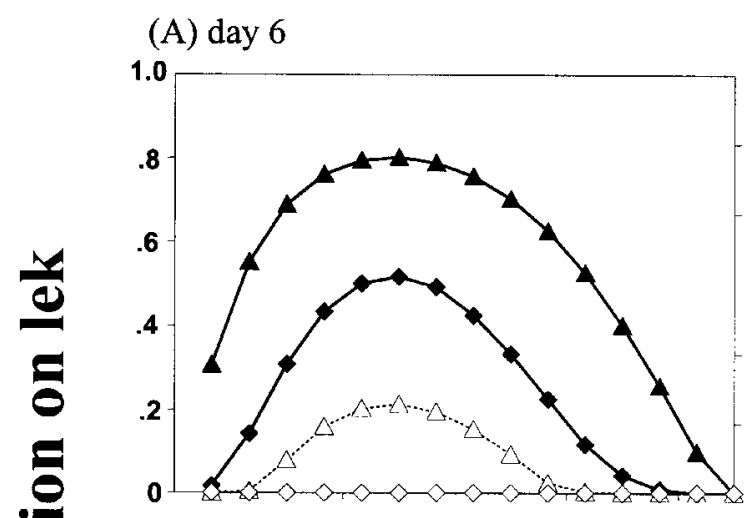

(B) day 21

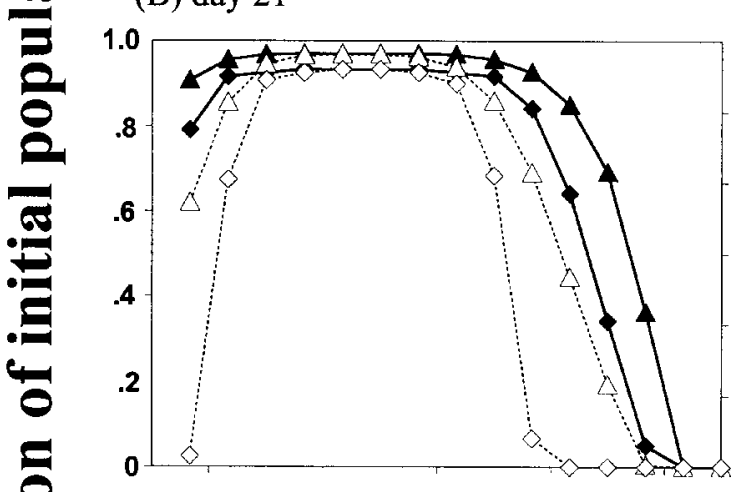

(C) day 36

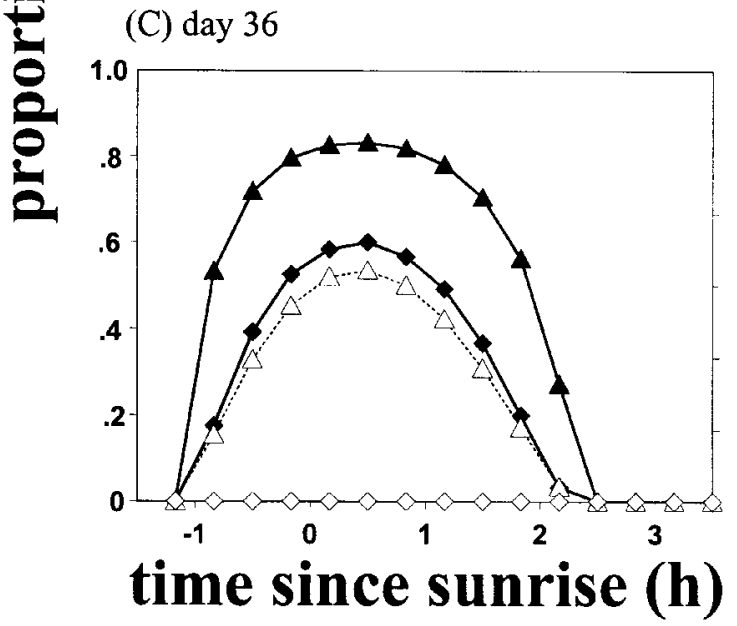

Figure 2: Population size effects: predicted lek sizes for populations of 12 (diamonds) and 50 (triangles) males. Lek size is plotted as a function of time of day at three times of year (days 6,21, and 36) and for calm (filled symbols, solid lines) and windy (open symbols, dashed lines) days. This simulation represents the baseline conditions.

ditions, all males appreciably reduced the amount of time they spent on the lek when predator arrival rates were doubled (fig. 4). Dominant males reduced their lekking time more than subordinates (not shown); thus, elevated 
predation risk drives subordinate and dominant males to synchronize their lekking behavior.

\section{Lek-Size-Dependent Female Arrival Rates}

It has often been suggested that females are more attracted to larger leks (Bradbury 1981; Alatalo et al. 1992; Lank and Smith 1992). We have not been able to support this suggestion in previous studies (Bradbury et al. 1989b; Gibson 1996), but because negative conclusions are not compelling, we modeled the effects of making female arrival rates dependent on lek size. We used three functions: no effect (baseline), square root (relatively weak effect), and squared (relatively strong effect). We calibrated these functions so that the average male mating success was identical for each, thus allowing us to manipulate female arrival lek-size dependence without manipulating overall female arrival intensity. In contrast to our results with predator arrival and lek size, female arrival lek-size dependence did affect lek dynamics considerably. As female arrival lek-size dependence increased, males spent less time on the lek and concentrated their efforts to periods of peak female availability (fig. 5). Dominants reduced their lekking time more than subordinates; thus lek-size-dependent female arrival synchronizes the lek in much the same way that elevated predation risk does.

We also simulated a lek with a female arrival rate that was twice the baseline rate, thereby altering female arrival rate without affecting its lek-size dependence. This did not affect male lekking behavior since male decisions are based on balancing current and future reproductive success, and both of these were doubled by the manipulation (although males were more sure of their decisions as an artifact of the probabilistic error function used). Thus, in contrast to the predator arrival rate data, the lek-size dependence of the female arrival rate function, but not its intensity, is important to male lekking behavior.

\section{Tests of the Model}

\section{Methods}

We tested several of the model's predictions about male departure times and daily lek attendance using 1,990 h (1,011 lek days) of observations at six sage grouse leks in Mono County, California. Our study areas, Wheeler Flat (1983) and Long Valley (1984-2001), are described by Bradbury et al. (1989a). Observers arrived at leks by 50 min before sunrise, at the onset of display, and usually stayed until the last birds departed. Behavioral sampling followed previous studies (Gibson et al. 1991; Gibson 1996; Semple et al. 2001). Lek observations provided counts of male and female numbers and departure time of the last
(A) day 6

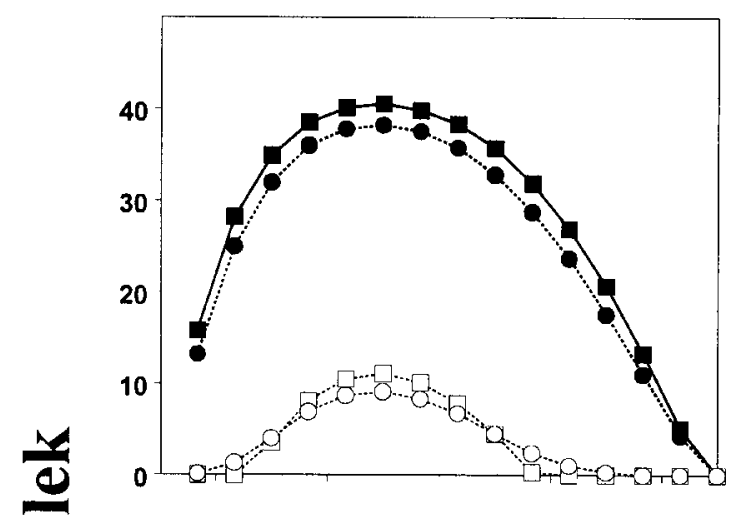

(B) day 21

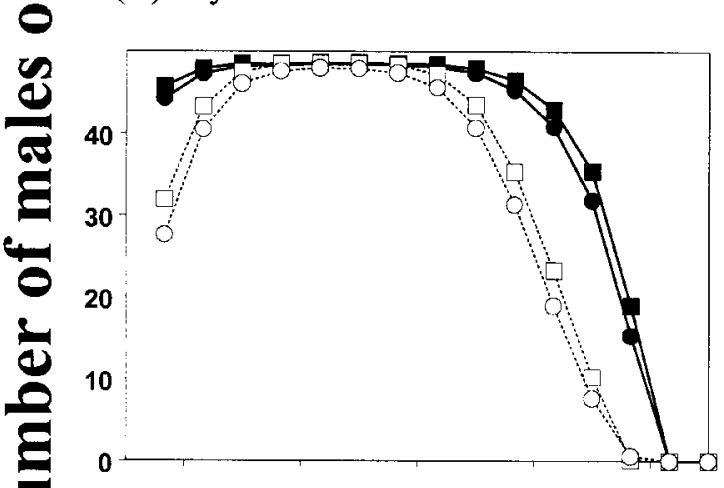

(C) day 36

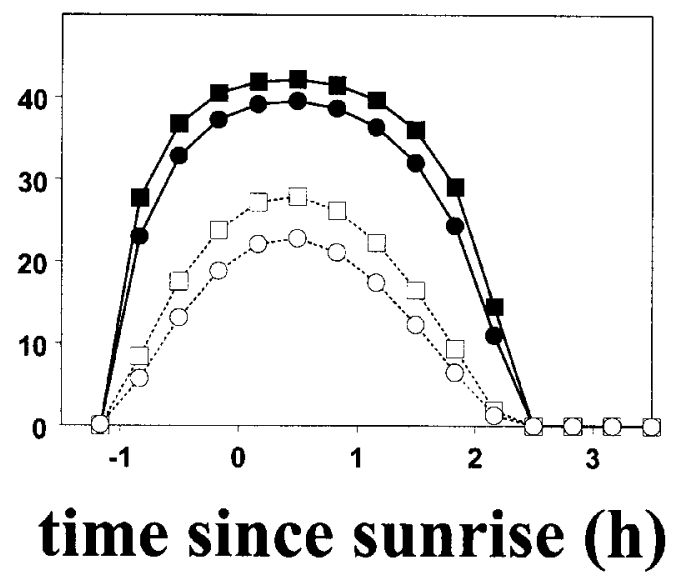

Figure 3: Male reproductive skew effect: predicted lek sizes based on a weak (squares $=$ square root $)$ or strong $($ circles $=$ squared $)$ effect of dominance status on male reproductive skew. Lek size is plotted as a function of time of day at three times of year (days 6, 21, and 36) and for calm (filled symbols, solid lines) and windy (open symbols, dashed lines) days. Neither predator arrival rate nor female arrival rate are assumed to be lek-size dependent. Initial population size is $\mathbf{5 0 .}$ 
(A) day 6
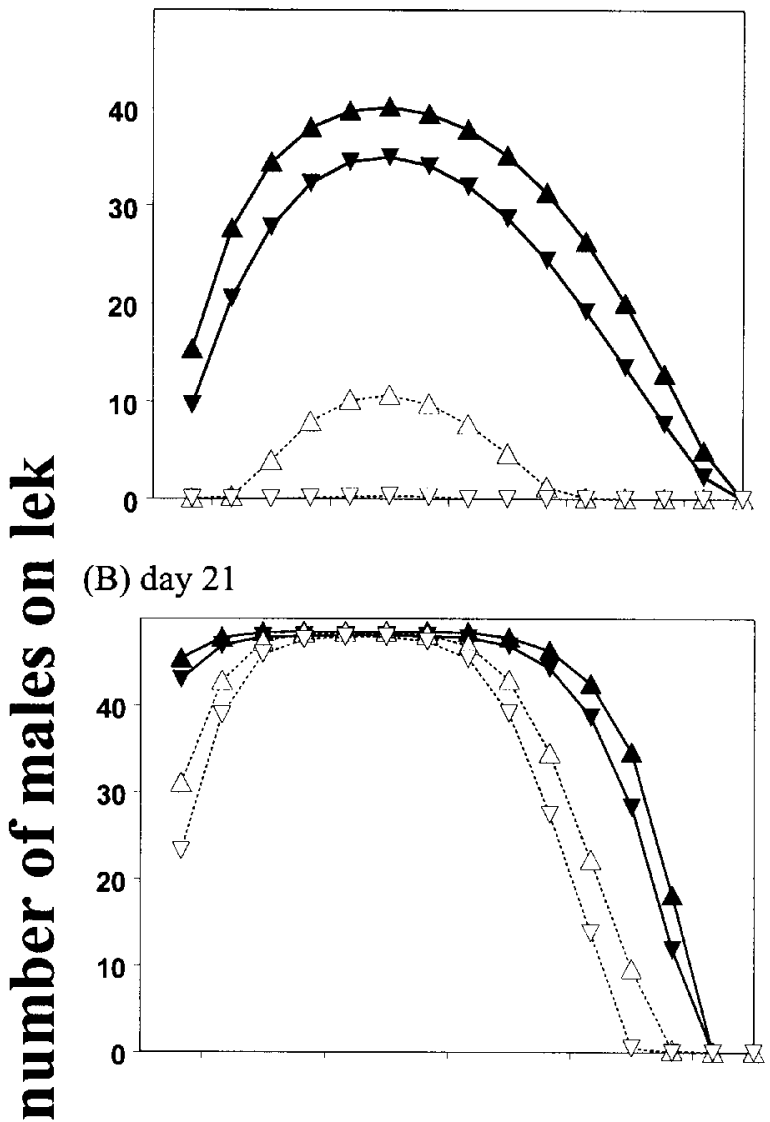

(C) day 36

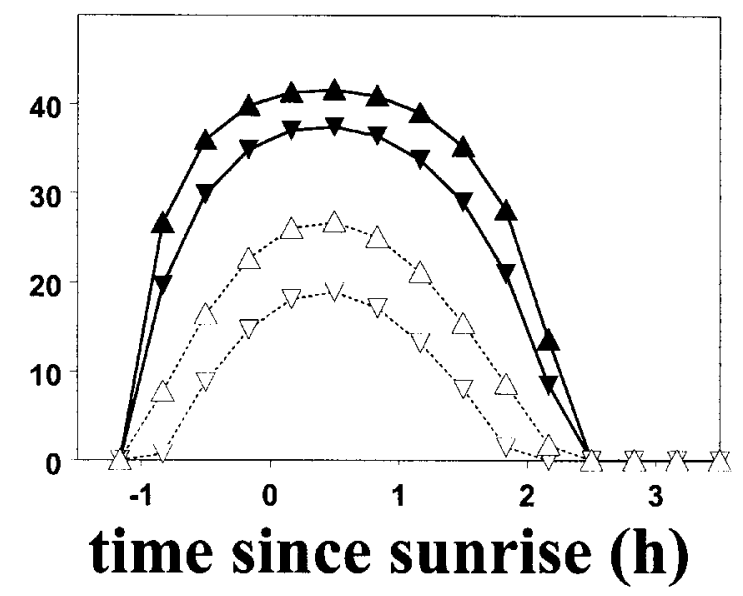

Figure 4: Effect of doubling predation risk: predicted lek sizes for baseline predation risk (triangles pointing up; see fig. 2 ) or $2 \times$ baseline predation risk (triangles pointing down). Lek size is plotted as a function of time of day at three times of year (days 6,21, and 36) and for calm (filled symbols, solid lines) and windy (open symbols, dashed lines) days. All other variables follow the baseline conditions. Initial population size is 50 . male. Because of low light levels, we did not systematically record male arrival times. Before analysis, male and female counts were, respectively, $\ln (X)$ and $\ln (1+X)$ transformed to remove right skew. Departure times were standardized to sunrise. For a subset of leks and years we collected detailed records of attendance and mating activity of individually recognizable (mostly color-banded) males. We systematically recorded departure times of individual males at one lek, Long Valley lek 4 (LV4), in 1998. From observers' records of weather conditions, we classified each lek day as either "calm" or "windy," corresponding to mean wind speeds of $0.8 \pm 0.3$ versus $2.8 \pm 2.2 \mathrm{~m} / \mathrm{s}$ recorded simultaneously at a weather station in Long Valley in observations totaling $3 \mathrm{yr}(N=60$ and $62 \mathrm{~d}$; MannWhitney test: $P<.0001)$.

We used mixed-model repeated-measures ANOVAs (Littell et al. 1996) to test for predicted effects of lek size, female numbers, and wind on male departure times within lek years. A similar repeated-measures analysis was used to test the effects of female numbers and wind on daily variation in male numbers. To control for possible serial dependence in departure times between successive days, a first-order autoregressive term was included in the model. The sample included 26 lek years with $\geq 10$ days sampled (751 lek days total). Departure time was measured as the time that the last male left the lek. Although males usually do not depart synchronously, daily variation in last male departure time was highly correlated with the mean departure time for all adult males at lek LV4 in 1998, when individual departure times of all territorial adult males were recorded ( $r=0.933, N=27 \mathrm{~d}, P<.0001)$. To ensure that any relationship between departure time and wind was not generated spuriously by the association between wind and disturbance of the lek by eagles, we excluded days in which males departed suddenly due to apparent disturbance (including eagle visits).

To test predicted effects of male "dominance" on individual departure times and lek attendance, we analyzed data on color-banded males of known mating success from LV4. In six different seasons, we analyzed individual daily attendance for males over a 35-d period starting $10 \mathrm{~d}$ before the first copulation of the year. To eliminate recording bias, the sample was limited to males color banded before the start of the sample period. Males were divided into high and low relative reproductive success categories (corresponding to "dominant" and "subordinate" categorization in the model) according to whether their summed copulations for the season exceeded or fell below the value expected if matings were randomly allocated among all males on days when they were present (Gibson et al. 1991). This measure corrects for variation in mating success due to differences in the opportunity to court receptive females. Males that attended only on days when 


\section{(A) day 6}

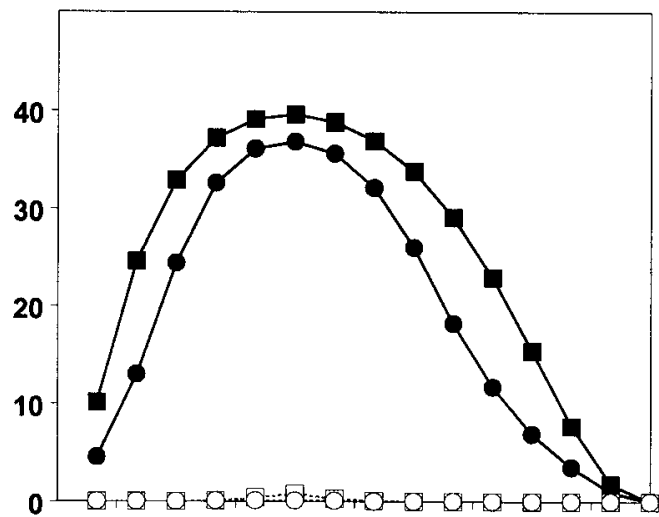

(B) day 21

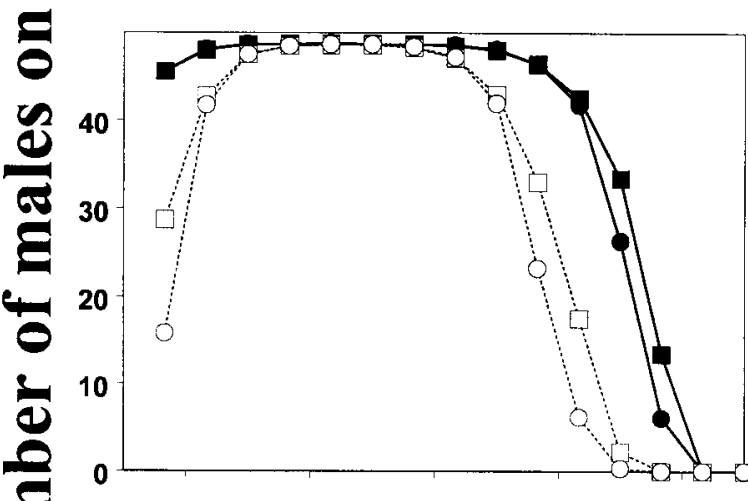

(C) day 36

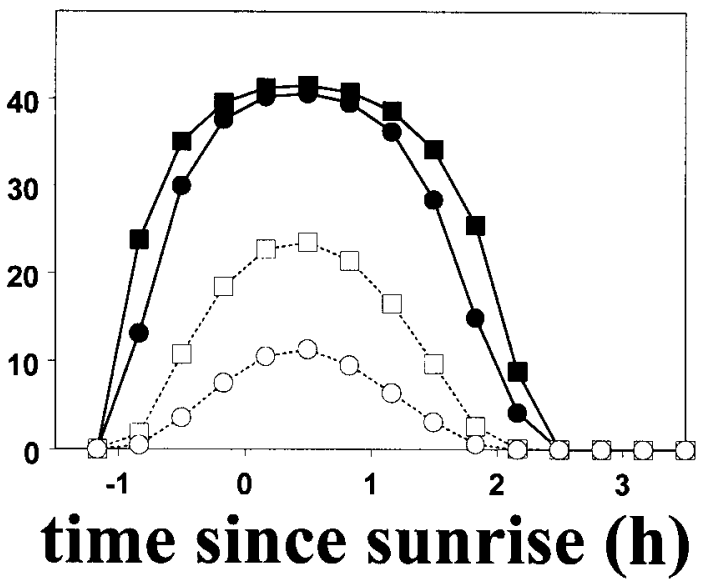

Figure 5: Lek-size-dependent female arrival rates: predicted lek sizes for weak $($ squares $=$ square root) or strong (circles $=$ squared) effect of lek size on female arrival rate. Lek size is plotted as a function of time of day at three times of year (days 6, 21, and 36) and for calm (filled symbols, solid lines) and windy (open symbols, dashed lines) days. All other variables follow the baseline conditions. Initial population size is 50 . there were no copulations could not be classified because both observed and expected matings were 0 . For individuals that were sampled in more than one year, we used only the first year's data.

\section{Results}

Lek Behavior. Our data strongly confirmed the predicted temporal patterns in male attendance within mornings. Males departed later on days when more females attended, when more males attended, and on calm rather than windy days (table 1). Also, as shown previously (Gibson 1996), male numbers tracked variation in female numbers during morning display periods (fig. 6).

Daily variation in lek size also conformed to the model's predictions, although less closely. As predicted, male numbers co-varied positively with numbers of females and tended to be lower on windy days (table 1). However, this analysis masks substantial variation in the former relationship across lek years. Positive relationships between male and female numbers were characteristic of small, but not large, leks. Across all 26 lek years, the slope of regression between $\ln$ (males) and $\ln (1+$ females $)$ decreased as mean male attendance increased $(r=-0.428, P=$ .025 ; fig. 7 provides an example from three leks studied in 2001).

Individual Behavior. Departure times of the six territorial adults at LV4 in 1998 were individually variable (Friedman two-way ANOVA by ranks: $\chi^{2}=21.56, \mathrm{df}=5, P=$ .0006). The two most successful males departed significantly later than all of the others (fig. 8), which is consistent with predicted later departure by "dominant" individuals.

Reproductively successful males both attended more of-

Table 1: Repeated-measures models fitted to last male departure time and daily male attendance within 26 lek years

\begin{tabular}{lrcc}
\hline $\begin{array}{l}\text { Dependent and } \\
\text { independent } \\
\text { variables }\end{array}$ & Coefficient $\pm \mathrm{SE}$ & $(\mathrm{df}=1,25)$ & $P$ \\
\hline $\begin{array}{l}\text { Departure time: } \\
\quad \text { Intercept }\end{array}$ & $-14.77 \pm 8.03$ & & \\
$\ln (1+$ females $)$ & $17.35 \pm 1.86$ & 86.99 & $<.0001$ \\
$\ln ($ males $)$ & $14.65 \pm 2.37$ & 38.30 & $<.0001$ \\
$\quad$ Wind & $12.17 \pm 3.14$ & 15.04 & $<.001$ \\
$\ln$ (males): & & & \\
$\quad$ Intercept & $2.92 \pm .09$ & & \\
$\quad \ln (1+$ females $)$ & $.15 \pm .02$ & 55.10 & $<.0001$ \\
$\quad$ Wind & $-.06 \pm .03$ & 3.91 & .06 \\
\hline
\end{tabular}

Note: Males $=$ number of males on the lek; females $=$ number of females on the lek; wind $=0$ (calm) or 1 (windy). 

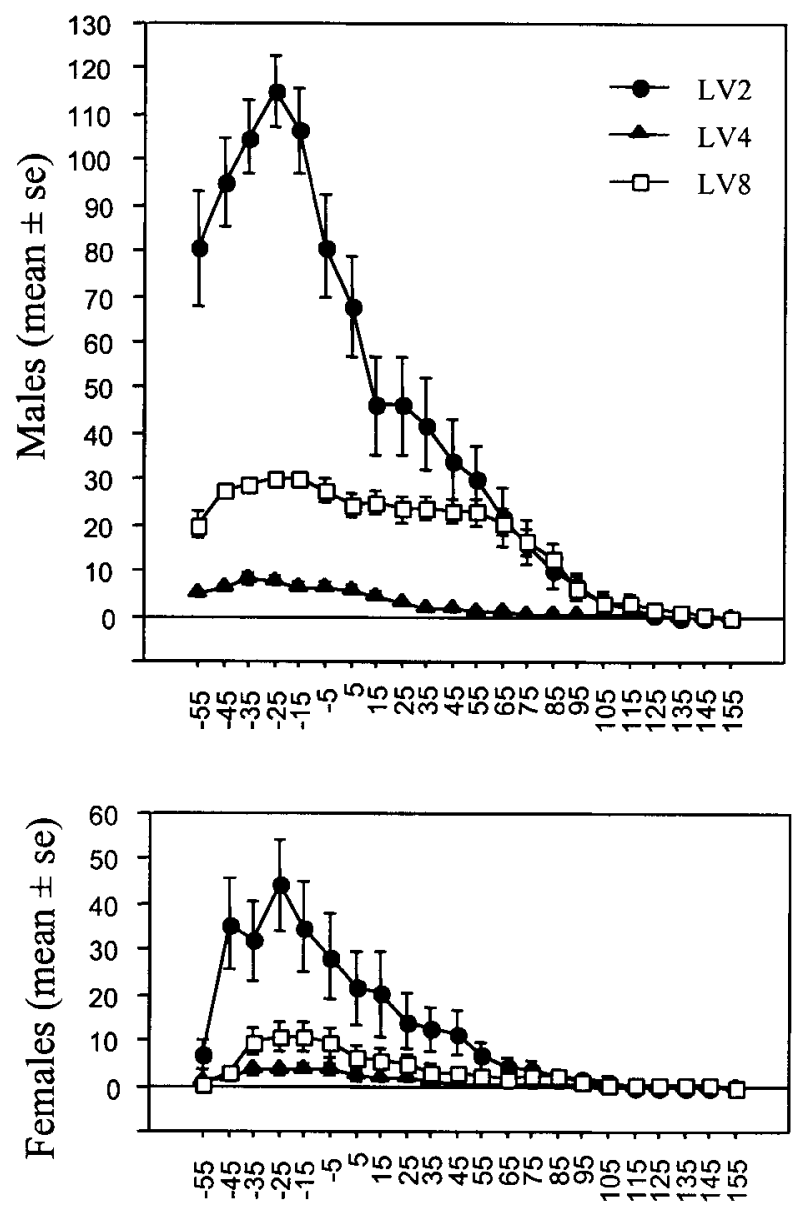

Minutes after sunrise (10 minute blocks)

Figure 6: Daily temporal profiles for male (upper) and female (lower) numbers at three leks counted simultaneously at 10-min intervals on 15 days in 2001. Log-transformed male and female numbers were positively correlated within 40 of 41 lek mornings when females attended (onesample $t=16.43, \mathrm{df}=40, P<.0001)$.

ten and differed from less successful individuals in their seasonal pattern of attendance (table 2). As predicted by the model, seasonal variation in attendance of less successful males more closely followed variation in female numbers (fig. 9). The fit is better in the rising than in the falling phase of female attendance: as female numbers dropped in the latter half of the breeding period, attendance by less reproductively successful males declined only slightly.

\section{Discussion}

In our model, attending a lek presents males with a tradeoff between mating opportunity and increased predation risk. Mating success, in turn, is affected by the number of males of each dominance class on the lek and by the degree to which females are attracted to the lek. Similarly, predation risk is affected by the number of males in the lek and the degree to which predators are attracted to the lek. Despite the complexity of the problem, the simulations show that a number of general patterns are expected. For example, lek attendance should roughly mirror the background arrival rate of females, peaking near dawn and near the midpoint of the season. Males should also spend more time at larger leks, where risk is more heavily diluted, and at times when predators are less likely to arrive (calm mornings). In addition, under all simulated conditions, dominant males should be the first to enter the lek and the last to leave.

Our analyses of daily variation in observed male departure times supported all of these general predictions. The model was slightly less successful in predicting variation in male attendance across days. Nevertheless, with exceptions discussed below, we still found that male attendance tracked female numbers over time, that males of lower relative mating success attended less frequently, and that their attendance was more closely linked to female availability. The model's success in predicting short-term lek dynamics suggests that male behavior is strongly affected by the trade-off between mating opportunity and predation risk.

This conclusion is subject to the caveat that some parts of the fit between predictions and data might be generated by other processes. For example, early departure on windy mornings might reduce thermoregulatory expenditures as

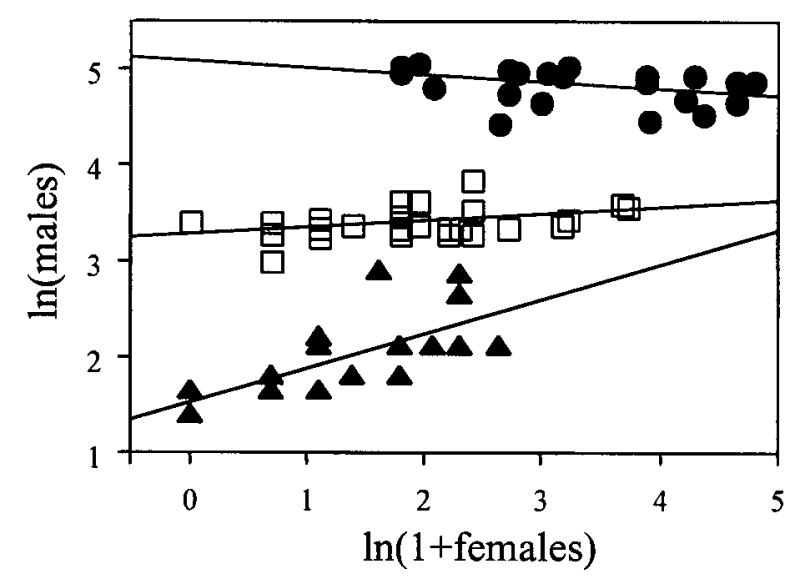

Figure 7: Relationships between male and female numbers across days at the three leks studied in 2001. Lek symbols are the same as in figure 6. Slopes differ between leks (ANCOVA, lek vs. female interaction: $F=12.01, \mathrm{df}=2,59, P<.001)$. Male numbers increased with females at leks LV4 and LV8 (simple regressions: $P=.006$ and .04 ) but tended to decrease at $\operatorname{LV} 2(P=.07)$. 


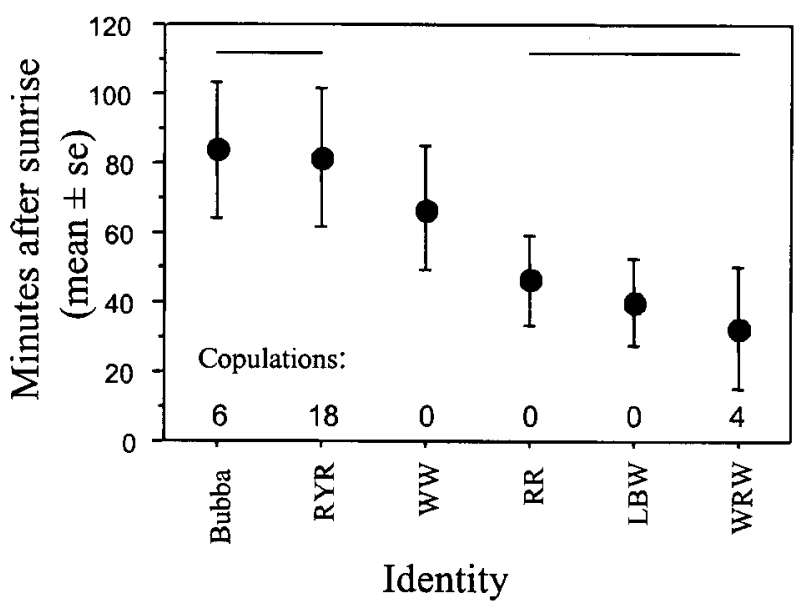

Figure 8: Mean lek departure time for all six territorial males at lek LV4 in 1998 on mornings when all attended. Horizontal lines join members of statistically homogeneous groups $(\alpha=0.05)$. Copulations per male are indicated below.

well as preempt eagle attack. Also, male departures might track female numbers within mornings partly because some males follow females off the lek and display to them in foraging areas (Gibson and Bradbury 1987). However, alternative scenarios do not explain all of the fit between predictions and data. For example, later male departure at larger leks, which in the model is a consequence of risk dilution, is not easily explained in other ways. This is important because dependence of departure time on lek size provides evidence that males reduce predation risk by displaying socially.

The poorer fit between predictions and variation in male attendance across days may be partly a result of the model's assumption that a lek is associated with a fixed pool of males $\left(N_{\max }\right)$. In reality, the pool will vary in size over time because some males change leks in response to differences in female availability (Gibson 1996) or attend leks more frequently as the season progresses (yearlings; Dalke et al. 1963). Both processes may explain why male and female numbers did not co-vary closely at the largest leks. In addition, at LV2 (the largest lek studied in 2001; fig. 7) a decline in male numbers during the peak of female attendance coincided with the appearance of several smaller leks nearby. As female attendance dropped, the new leks disappeared and the size of LV2 increased, which suggests that a common pool of males was involved. Similar observations were made in some other years. This provides a third mechanism decoupling male and female attendance at the largest leks. However, this is also consistent with the model's prediction that males will display at the smallest leks only when female arrival rates peak.
In addition to the basic predictions that were amenable to testing, the model identifies several factors affecting the degree of synchrony in lek attendance shown by males of different quality. Obviously, as mating skew increases, synchrony will decline, especially at times of low female arrival rates. Less obviously, absolute predator arrival rates but not absolute female arrival rates will increase lek synchrony. Females can drive lek synchrony, however, if they are attracted to large leks (i.e., if female arrival is lek-size dependent). Not surprisingly, leks are less likely to form on "marginal" days if females are more strongly attracted to large leks or if the general predation risk on the lek is elevated. The lack of an effect on behavior caused by leksize-dependent predation risk and the presence of lek-size dependence in response to female arrival rates supports similar results derived by Lucas and Howard (1995) and Lucas et al. (1996) in their model of alternative mating tactics in anurans. These results suggest that a rough estimate of predation risk is sufficient to characterize the salient features of the effect of predation on lekking behavior. This is important since predation risk is usually difficult to quantify and the details of lek-size-dependent predation risk may be impossible to measure for most lekking species (Marshal and Boutin 1999).

The model also suggests novel interpretations for at least two phenomena that play important roles in alternative models of lek formation. First, under all simulated conditions, dominant males should be the first to enter the lek and the last to leave. This pattern superficially mimics that described in the "hotshot" model (Beehler and Foster 1988; Gibson 1992), where low-quality males aggregate around high-quality males in order to intercept females attracted to the latter. However, our model offers an alternative explanation for this pattern. Dominant males can afford to enter the lek at lower female arrival rates because they have priority of access to the few available females at these times. In contrast, low-quality males delay entering

Table 2: Repeated-measures model fitted to individual lek attendance

\begin{tabular}{|c|c|c|c|c|}
\hline Independent variable & Coefficient \pm SE & $F$ & df & $P$ \\
\hline \multicolumn{5}{|l|}{ Reproductive status: } \\
\hline Low & $.2536 \pm .0758$ & 26.10 & 2,37 & $<.0001$ \\
\hline High & $.6860 \pm .1071$ & & & \\
\hline Date & $.0132 \pm .0115$ & 17.85 & 1,37 & .0001 \\
\hline Date $^{2}$ & $-.0003 \pm .0003$ & 12.84 & 1,37 & .001 \\
\hline \multicolumn{5}{|l|}{ Reproductive status } \\
\hline$\times$ date & $.0332 \pm .0141$ & 5.43 & 1,37 & .02 \\
\hline \multicolumn{5}{|l|}{ Reproductive status } \\
\hline$\times$ date $^{2}$ & $-.0008 \pm .0004$ & 4.31 & 1,37 & .04 \\
\hline
\end{tabular}

Note: $N=39$ adult males. Date refers to the midpoints of 5 -d blocks shown in figure 9; reproductive status is defined as below the value expected from lek attendance (low) or above it (high). 


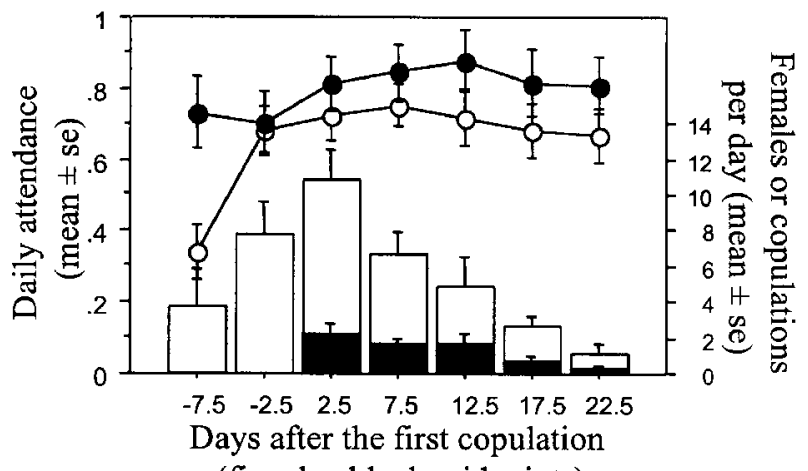

(five day block midpoints)

Figure 9: The seasonal pattern of lek attendance for males of high (filled circles) and low (open circles) relative mating success. Bars indicate female arrival (open) and copulation (filled) rates. Data are grouped into 5-d blocks starting $10 \mathrm{~d}$ before mating. For statistical analysis see table 2 .

the lek because they have less access to females but would still be under an increased predation threat on, compared with off, the lek. Once high-quality males enter the lek, predation risk for low-quality males is diluted, therefore increasing the chance that they will also enter.

The model also predicts that when mating skew increases, lek size will decline because subordinate males attend less. This in turn could generate a negative relationship between skew and mean lek size. This relationship has been described in a variety of lekking species (Widemo and Owens 1995, 1999) and has previously been attributed to both increased rates of male aggression (Widemo and Owens 1999) and decreased accuracy of female choice (Johnstone and Earn 1999) in larger leks. Our model suggests an additional mechanism: high skew can cause lek size to decrease through indirect effects of predation. Reduced skew on larger leks underpins Widemo and Owens's (1995) model in which poor quality males join larger leks because these provide more equitable mating opportunities (though see also Kokko et al. 1998). In view of its potential importance in lek dynamics, the proximate causation of this relationship warrants further analysis.

Our analysis illustrates that the behavior of lekking males can reveal the influence of predation even though predation itself is rarely observed. To what extent are our conclusions likely to apply to other lekking systems? Sage grouse are subject to higher annual mortality and more on-lek predation than some longer-lived avian species such as manakins (Lill 1974, 1976; McDonald 1989). We acknowledge that predation may not be relevant to all lek systems (e.g., marine iguanas; Wikelski et al. 1996); nevertheless, because almost all lekking birds are potentially subject to predation when displaying, our analysis is likely to be relevant even to species such as manakins that experience infrequent predation.

We base this suggestion on two relevant features of the model. First, courtship display attracts predators. Although field data on predation rates from avian leks are mostly inconclusive on this point, other evidence suggests that display does increase male exposure to predation. For example, in sexually dichromatic species, subadult males commonly retain cryptic female plumage until they begin to compete at leks (Lill 1974, 1976; McDonald 1989), and adult males may molt conspicuous nuptial plumage immediately after breeding (van Rhijn 1991). Additionally, in three lekking rainforest birds studied by Endler and Thery (1996), including two manakins, adult males may utilize light environments that reduce the visual contrast (conspicuousness) of their plumage, except during bouts of sexual display when they occupy microhabitats-for example, sun spots - that increase visual contrast. Second, in the model, behavioral sensitivity to the threat of predation increases with both the probability of predator arrival at the lek and the value of expected future reproduction. It is thus not obvious that longer-lived species such as manakins, which would score low on the former but high on the latter, should be less predator sensitive than shorter-lived sage grouse, in which the weightings are reversed. Resolution of this issue requires empirical study.

Lack (1968) argued that predation was an important ecological determinant of aggregated male display, although he did not rule out a concurrent role for sexual selection. However, later ecologically based syntheses of mating system evolution that extended many of Lack's ideas downplayed his view of leks in favor of mechanisms driven by sexual selection (Emlen and Oring 1977; Bradbury 1981; though see Oring 1982). Subsequent work has largely followed the latter path. Recently we have provided indirect evidence that males may join leks to reduce predation by showing that other grouse species actively form mixed-species leks even though this does not increase mating opportunities for males of the joining species (Gibson et al. 2002). Our demonstration here that short-term lek dynamics can be explained by a model based on the natural history of interactions between a lekking bird and one of its principal predators provides more specific evidence for the influence of predation on lek dynamics. On its own this does not necessarily support Lack's view that males lek to reduce predation. However, the latter inference is supported by our finding that males depart later from larger leks. It will be important to assess the generality of our conclusions in other lek systems, particularly ones that are more amenable to experimental analysis. Although our analysis has been limited to male behavior, multiple components of male and female courtship behavior may be sensitive to predation risk (Candolin 1997 and references 
therein; Candolin and Voight 1998; Warner and Dill 2000). Further analysis from this perspective has the potential to substantially enrich our understanding of lek dynamics.

\section{Acknowledgments}

Collection of field data was funded by grants from the National Science Foundation (currently IBN-0078013 to R.M.G.) supplemented by the biology departments at University of California, Los Angeles, and University of Nebraska, Lincoln, and involved the participation of over 50 undergraduate and graduate assistants. We are particularly indebted to J. Bradbury for sharing data from the early 1980 s and to K. Semple for records of male departure times in 1998. We thank D. Dawson and the University of California Natural Reserve System for logistical support over many years. We also thank two anonymous reviewers for their helpful comments on this manuscript.

\section{Literature Cited}

Alatalo, R. V., J. Höglund, A. Lundberg, and W. J. Sutherland. 1992. Evolution of black grouse leks: female preferences benefit males in larger leks. Behavioral Ecology 3:53-59.

Andersson, M. 1994. Sexual selection. Princeton University Press, Princeton, N.J.

Beehler, B. M., and M. Foster. 1988. Hotshots, hotspots, and female preference in the organization of lek mating systems. American Naturalist 131:203-219.

Bradbury, J. W. 1981. The evolution of leks. Pages 138169 in R. D. Alexander and D. W. Tinkle, eds. Natural selection and social behavior. Chiron, New York.

Bradbury, J. W., R. M. Gibson, and I. M. Tsai. 1986. Hotspots and the dispersion of leks. Animal Behaviour 34: 1694-1709.

Bradbury, J. W., S. L. Vehrencamp, and R. M. Gibson. 1989a. Dispersion of displaying male sage grouse. I. Patterns of temporal variation. Behavioral Ecology and Sociobiology 24:1-14.

Bradbury, J. W., R. M. Gibson, C. McCarthy, and S. L. Vehrencamp. 1989b. Dispersion of displaying male sage grouse. II. The role of female dispersion. Behavioral Ecology and Sociobiology 24:15-24.

Candolin, U. 1997. Predation risk affects courtship and attractiveness of competing threespine stickleback males. Behavioral Ecology and Sociobiology 41:81-87.

Candolin, U., and H. R. Voight. 1998. Predator-induced nest site preference: safe nests allow courtship in sticklebacks. Animal Behaviour 56:1205-1211.

Dalke, P. D., D. B. Pyrah, D. C. Stanton, J. E. Crawford, and W. F. Schlatterer. 1963. Ecology, productivity and management of sage grouse in Idaho. Journal of Wildlife Management 27:811-840.
Dehn, M. M. 1990. Vigilance for predators: detection and dilution effects. Behavioral Ecology and Sociobiology 26:337-342.

Emlen, S. T., and L. W. Oring. 1977. Ecology, sexual selection, and evolution of mating systems. Science 197: 215-223.

Endler, J. A., and M. Thery. 1996. Interacting effects of lek placement, display behavior, ambient light, and color patterns in three Neotropical forest-dwelling birds. American Naturalist 148:421-452.

Gibson, R. M. 1992. Lek formation in sage grouse: the effect of female choice on male territory settlement. Animal Behaviour 43:443-450.

1996. A re-evaluation of hotspot settlement in lekking sage grouse. Animal Behaviour 52:993-1005.

Gibson, R. M., and G. C. Bachman. 1992. The costs of female choice in a lekking bird. Behavioral Ecology 3: 300-309.

Gibson, R. M., and J. W. Bradbury. 1985. Sexual selection in lekking sage grouse: phenotypic correlates of male mating success. Behavioral Ecology and Sociobiology 18: $117-123$.

- 1987. Lek organization in sage grouse: variations on a territorial theme. Auk 104:77-84.

Gibson, R. M., J. W. Bradbury, and S. L. Vehrencamp. 1991. Mate choice in lekking sage grouse revisited, the roles of vocal display, female site fidelity and copying. Behavioral Ecology 2:165-180.

Gibson, R. M., A. S. Aspbury, and L. L. McDaniel. 2002. Active formation of mixed-species grouse leks: a role for predation in lek evolution? Proceedings of the Royal Society of London B 269:2503-2507.

Hamilton, W. D. 1971. Geometry for the selfish herd. Journal of Theoretical Biology 31:295-311.

Hartzler, J. E. 1974. Predation and the daily timing of sage grouse leks. Auk 91:532-536.

Höglund, J., and R. V. Alatalo. 1995. Leks. Princeton University Press, Princeton, N.J.

Houston, A. I., and J. M. McNamara. 1987. Singing to attract a mate: a stochastic dynamic game. Journal of Theoretical Biology 129:57-68.

- 1999. Models of adaptive behaviour: an approach based on state. Cambridge University Press, Cambridge.

Johnstone, R. A., and D. J. D. Earn. 1999. Imperfect female choice and male mating skew on leks of different sizes. Behavioral Ecology and Sociobiology 45:277-281.

Kalas, J. A., P. Fiske, and S. A. Saether. 1995. The effect of mating probability on risk taking: an experimental study in lekking great snipe. American Naturalist 146: 59-71.

Kokko, H. 1997. The lekking game: can female choice explain aggregated male displays? Journal of Theoretical Biology 187:57-64. 
Kokko, H., W. J. Sutherland, J. Lindstrom, J. Reynolds, and A. MacKenzie. 1998. Individual mating success, lek stability, and the neglected limitations of statistical power. Animal Behaviour 56:755-762.

Lack, D. 1968. Ecological adaptations for breeding in birds. Methuen, London.

Lank, D. B., and C. M. Smith. 1992. Females prefer larger leks: field experiments with ruffs (Philomachus pugnax). Behavioral Ecology and Sociobiology 30:323-329.

Lill, A. 1974. Social organization and space utilization in the lek-forming white bearded manakin, M. mancus trinitatis Hartert. Zeitschrift für Tierpsychologie 36: 513-530.

. 1976. Lek behavior in the golden-headed manakin, Pipra erythrocephala, in Trinidad (West Indies). Zeitschrift für Tierpsychologie 18(suppl.):1-84.

Littell, R. C., G. A. Milliken, W. W. Stroup, and R. D. Wolfinger. 1996. SAS system for mixed models. SAS Institute, Cary, N.C.

Lucas, J. R., and R. D. Howard. 1995. On alternative reproductive tactics in anurans: dynamic games with density and frequency dependence. American Naturalist 146:365-397.

Lucas, J. R., R. D. Howard, and J. G. Palmer. 1996. Callers and satellites: chorus behaviour in anurans as a stochastic dynamic game. Animal Behaviour 51:501-518.

Marshal, J. P., and S. Boutin. 1999. Power analysis of wolfmoose functional responses. Journal of Wildlife Management 63:396-402.

McDonald, D. B. 1989. Cooperation under sexual selection: age-graded changes in a lekking bird. American Naturalist 134:709-730.

McNamara, J. M., J. N. Webb, E. J. Collins, T. Szekely, and A. I. Houston. 1997. A general technique for computing evolutionarily stable strategies based on errors in decision-making. Journal of Theoretical Biology 189: 211-225.
Neems, R. M., J. Lazarus, and A. J. Mclachlan. 1992. Swarming behavior in male chironomid midges: a cost benefit analysis. Behavioral Ecology 3:285-290.

Oring, L. W. 1982. Avian mating systems. Pages 1-92 in D. S. Farner, J. R. King, and K. C. Parkes, eds. Avian biology. Academic Press, New York.

Pulliam, H. R., and T. Caraco. 1984. Living in groups: is there an optimal group size? Pages 122-147 in J. R. Krebs and N. B. Davis, eds. Behavioural ecology. 2d ed. Blackwell Scientific, Oxford.

Ryan, M. J., M. D. Tuttle, and L. K. Taft. 1981. The costs and benefits of frog chorusing behavior. Behavioral Ecology and Sociobiology 8:273-278.

Semple, K. E., R. K. Wayne, and R. M. Gibson. 2001. Microsatellite analysis of female mating behavior in lekbreeding sage grouse. Molecular Ecology 10:2043-2048.

Trail, P. W. 1987. Predation and antipredator behavior at Guianan cock-of-the-rock leks. Auk 104:496-507.

van Rhijn, J. G. 1991. The ruff. Poyser, London.

Warner, R. R., and L. M. Dill. 2000. Courtship displays and coloration as indicators of safety rather than of male quality: the safety assurance hypothesis. Behavioral Ecology 11:444-451.

Widemo, F., and I. P. F. Owens. 1995. Lek size, male mating skew, and the evolution of lekking. Nature 373:148-151. 1999. Size and stability of vertebrate leks. Animal Behaviour 58:1217-1221.

Wikelski, M., C. Carbone, and F. Trillmich. 1996. Lekking in marine iguanas: female grouping and male reproductive strategies. Animal Behaviour 52:581-596.

Wiley, R. H. 1973. Territoriality and non-random mating in sage grouse, Centrocercus urophasianus. Animal Behavior Monographs 6:87-169.

- 1974. Evolution of social organization and life history patterns among grouse. Quarterly Review of Biology 49:201-227. 